\title{
VARIABILITAS FENOTIPIK TANAMAN GAMBIR DI DESA TANJUNG, KECAMATAN KOTO KAMPAR HULU KABUPATEN KAMPAR
}

\author{
SEPRITA LIDAR ${ }^{{ }^{*}}$, ENNY MUTRYARNY ${ }^{1}$,TRISIA WULANTIKA ${ }^{1}$ \\ ${ }^{1}$ Program Studi Agroteknologi, Fakultas Pertanian, Universitas Lancang Kuning, \\ Jl.Yos Sudarso Km 8,Rumbai Pekanbaru Riau \\ "Email: Ita_sldr@yahoo.com
}

\begin{abstract}
ABSTRAK
Gambir merupakan salah satu komoditas perkebunan rakyat yang bernilai ekonomi tinggi dan prospektif untuk dikembangkan secara komersial pada masa yang akan datang. Provinsi Riau termasuk penghasil gambir dimana Kecamatan yang memiliki perkebunan gambir paling luas adalah Kecamatan Koto Kampar Hulu Kabupaten Kampar seluas 4.104 Penelitian dengan judul "Analisis Variabilitas Fenotipik Tanaman Gambir di Desa Tanjung, Kec. Koto Kampar Hulu, Kabupaten Kampar" telah dilakukan pada bulan Maret-April 2018 , Metode penelitian menggunakan metode purposive sampling, sampel diambil sebanyak 30 aksesi kemudian analisis kemiripan menggunakan program ntsys ver 2.02. Diperoleh Hasil Variabilitas sempit pada semua karakter pengamatan. Koefisien kemiripan aksesi gambir berkisar 0,33-0,93
\end{abstract}

Kata kunci: Gambir, Variabilitas, Plasma Nutfah, Karakterisasi, Fenotipik

\begin{abstract}
Gambier is one commodity that is worth people's plantation economy and prospective for higher developed commercially in the future. Riau Province gambir Subdistrict where producers including the Gambier plantation had the most extensive is a subdistrict of Koto Kampar Kampar Regency acres 4,104 Upstream Research entitled "analysis ofthe Phenotypic variability of Gambir Plant in the village of Tanjung, Kec. Koto Kampar, Kampar Regency of Hulu "has been conducted in March - April 2018, research method using the method of purposive sampling, the samples taken 30 accession later analysis of similarity using the ntsys program ver 2.02. Obtained Results narrow Variability on all character observations. Similarity coefficient gambir accessions ranged from 0.33-0.93.
\end{abstract}

Keywords: Gambir, Variability, Germplasm, Phenotypic Characterization

Diterima: 20 Juli 2018, disetujui : 26 Juli 2018

\section{PENDAHULUAN}

Gambir merupakan salah satu bentuk getah yang dikeringkan yang komoditi pertanian yang penting, karena berasal dari ekstrak remasan daun dan mempunyai nilai ekonomi yang cukup ranting tumbuhan gambir yang telah tinggi. Gambir ini diperdagangkan dalam diolah dan dicetak berbentuk silinder. 
Gambir dapat dipergunakan sebagai bahan baku dalam industri farmasi, industri kosmetik, industri batik, industri cat, industri penyamak kulit, biopestisida, hormon pertumbuhan, pigmen, dan sebagai campuran bahan pelengkap makanan. Di Indonesia dan India umumnya gambir digunakan untuk menyirih, bahkan India mengimpor $68 \%$ dari Indonesia dan menggunakannya sebagai bahan campuran menyirih. Sejalan dengan berkembangnya negaranegara industri yang memproduksi jenisjenis barang yang memerlukan bahan baku ataupun bahan penolong gambir, maka kebutuhan gambir dalam industri semakin diperlukan, dengan demikian pengembangan ekspor gambir masih mempunyai potensi untuk dikembangkan. Pangsa pasar gambir masih cukup baik karena Indonesia baru memasok 2,43\% dari kebutuhan dunia (Denian, 2008).

Pemuliaan tanaman merupakan suatu seni, ilmu dan teknologi atau metode yang merakit keragaman genetik tanaman menjadi suatu bentuk yang lebih bermanfaat bagi kebutuhan masyarakat. Plasma nutfah adalah bahan baku dasar pemuliaan karena di sini tersimpan

\section{METODE PENELITIAN}

Penelitian ini telah dilaksanakan di Desa Tanjung, Kecamatan Koto Kampar Hulu, Kabupaten Kampar pada bulan Maret sampai April 2018

Bahan yang digunakan dalam penelitian ini adalah tanaman gambir dan kuisioner. Alat yang digunakan adalah mistar, meteran, literan, kantong plastik, kamera digital, GPS (globalpositionsystem), kertas label, tangga, pisau ,parang,colourchart, smartmeasure, jangka, timbangan ,jangkasorong dan alat-alat tulis.

Metode yang digunakan adalah survey dengan pengambilan sampel secara sengaja (PurpossiveSampling). Jumlah sampel yang akan diambil adalah berbagai keanekaragaman sifat yang dimiliki oleh masing-masing nomor koleksi (aksesi). Tanpa keanekaragaman, perbaikan sifat tidak mungkin dilakukan. Ketersediaan sumberdaya genetik atau plasma nutfah dengan variabilitas genetik yang cukup luas dan informasi genetik yang akurat merupakan salah satu faktor esensial dalam program pemuliaan tanaman. Tanpa tersedianya plasma nutfah dengan variabilitas yang luas, maka kegiatan pemuliaan tanaman tidak akan berjalan efektif. Upaya merakit kultivar unggul baru akan mengalami kesulitan karena sumber karakter-karakter unggul tertentu yang diinginkan sulit atau bahkan tidak dapat ditemukan dalam plasma nutfah yang ada. Oleh karena itu perlu dilakukan penelitian dengan judul "Variabilitas Fenotipik Tanaman Gambir di Desa Tanjung, Kecamatan Koto Kampar Hulu, Kabupaten Kampar". Penelitian ini bertujuan untuk Mengetahui tingkat keragaman serta karakteristik morfologi plasma nutfah gambir di Desa Tanjung, Kec.Koto Kampar Hulu, Kab.Kampar sehingga nantinya dapat memberikan informasi awal bagi pemulia tanaman.

sebanyak 30 aksesi. Pengambilan data dan pengamatan dilakukan secara langsung terhadap tanaman gambir. Data morfologi ditampilkan secara deskriptif, analisis kemiripan menggunakan program Ntsys Ver.2.02.

Pelaksanaan Penelitian

1. Studi pendahuluan

Studi Pendahuluan dilakukan untuk menentukan 30 aksesi yang akan dijadikan sampel penelitian.

2. Lokasi koordinat tanaman dengan GPS (Global Positioning System)

Data yang diambil berupa tinggi tempat,letak geografis.

3. Karakterisasi 
Karakterisasi berdasarkan karakter mendokumentasikan secara langsung yang morfologi tanaman gambir dengan berhubungan dengan variabel mengamati, mengukur dan pengamatan.

\section{HASIL DAN PEMBAHASAN}

Penelitian ini telah dilakukan di Desa Tanjung, Kec.Koto Kampar Hulu, Kabupaten Kampar.Provinsi Riau. Kab Kampar memiliki luas $11289,28 \mathrm{Km}^{2}$. Terdiri dari 21 kecamatan dan 250 Desa/Kelurahan. Luas kecamatan koto kampar hulu : $674 \mathrm{Km}^{2}$. Berdasarkan hasil identifikasi karakter fenotipik pada 30 aksesi tanaman gambir, nilai kisaran

dan nilai rata-ratanya dapat dilihat dalam Tabel 1. Pengamatan pada bunga dan buah tidak dilakukan pada semua sampel karena pada saat pengambilan sampel tidak semua tanaman dalam kondisi berbunga dan berbuah. Tabel 1 menunjukkan bahwa data tanaman gambir menunjukkan hasil yang bervariasi.

Tabel 1. Nilai kisaran dan rata-rata hasil identifikasi karakter fenotipik tanaman gambir di Desa Tanjung

\begin{tabular}{|c|c|c|c|}
\hline Karakter & & Kisaran & Rata-rata \\
\hline Sudut cabang $\left(^{\circ}\right)$ & 32,5 & 65,3 & 54,6 \\
\hline Panjang ruas $(\mathrm{cm})$ & 2,1 & 9,12 & 6,48 \\
\hline Diameter cabang (mm) & 0,5 & 8,15 & 5,60 \\
\hline Permukaan cabang & Halus & kasar & Halus \\
\hline Warna permukaan cabang & Hijau muda & cokelat tua & Cokelat tua \\
\hline Bentuk helaian daun & Bulat & $\begin{array}{l}-\quad \text { jorong } \\
\text { memanjang }\end{array}$ & Bulat \\
\hline Bentuk ujung daun & Runcing & meruncing & Meruncing \\
\hline Bentuk pangkal daun & Runcing & tumpul & Tumpul \\
\hline Panjang tangkai daun $(\mathrm{cm})$ & 0,2 & $-\quad 1,15$ & 0,72 \\
\hline Diameter tangkai daun (mm) & 1,78 & 3,2 & 2,31 \\
\hline Panjang daun $(\mathrm{cm})$ & 6,1 & 12,4 & 8,4 \\
\hline Lebar daun $(\mathrm{cm})$ & 4,38 & 9,21 & 6,11 \\
\hline Tebal daun (mm) & 0,28 & 0,69 & 0,18 \\
\hline Luas satu helai daun $\left(\mathrm{cm}^{2}\right)$ & 39,2 & 156,02 & 75,38 \\
\hline Bobot satu helai daun (g) & 0,56 & 3,07 & 1,48 \\
\hline Permukaan atas helaian daun & Licin & kasar & Licin \\
\hline Permukaan bawah helaian daun & Licin & kasar & Kasar \\
\hline $\begin{array}{l}\text { Warna permukaan helaian daun } \\
\text { bagian atas }\end{array}$ & Hijau tua & merah tua & Hijau muda \\
\hline $\begin{array}{l}\text { Warna permukaan helaian daun } \\
\text { bagian bawah }\end{array}$ & Hijau tua & merah tua & Hijau merah \\
\hline Warna tulang daun & Hijau muda & & Hijau muda \\
\hline Warna pupus & Hijau muda & & Hijau muda \\
\hline Tepi daun & Rata & & Rata \\
\hline Panjang tangkai bunga $(\mathrm{cm})$ & 1,45 & 4,3 & 2,51 \\
\hline Diameter tangkai bunga (mm) & 1,24 & 3,07 & 2,16 \\
\hline Warna tangkai bunga & Hijau muda & cokelat tua & Hijau muda \\
\hline Diameter bunga (cm) & 0,25 & 2,39 & 0,82 \\
\hline Panjang tangkai buah (cm) & 2,3 & 5,4 & 3,37 \\
\hline Diameter tangkai buah (mm) & 1,5 & 3,3 & 2,5 \\
\hline Warna buah muda & Hijau muda & hijau merah & Hijau merah \\
\hline Warna buah matang & Cokelat tua & hitam & Hitam \\
\hline
\end{tabular}




\begin{tabular}{|c|c|c|c|}
\hline Panjang buah $(\mathrm{cm})$ & 2,4 & 3,85 & 3,18 \\
\hline Lingkar buah $(\mathrm{cm})$ & 0,27 & 0,38 & 0,36 \\
\hline
\end{tabular}
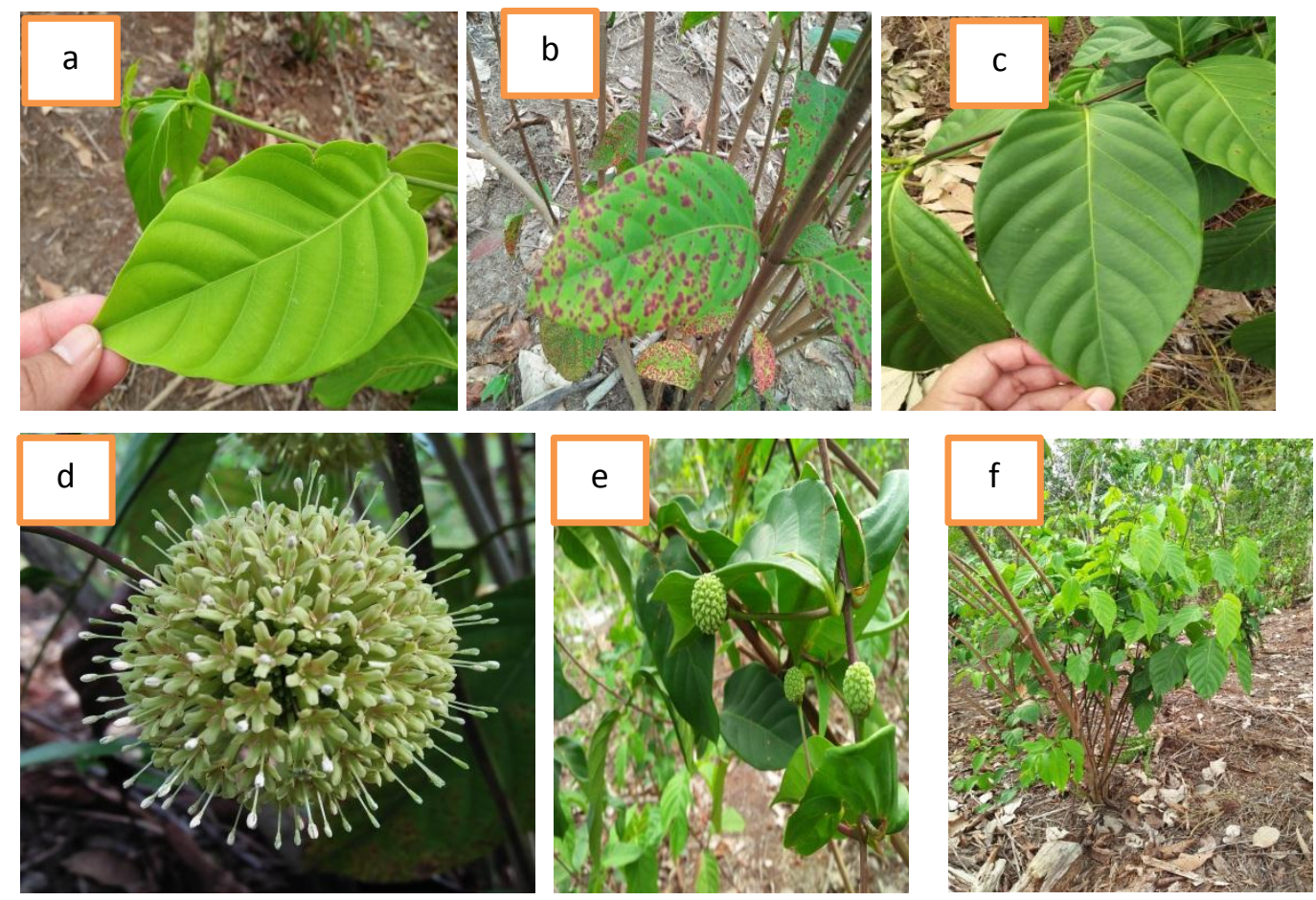

Gambar 1. penampilan fenotipe gambir; Keterangan : a,b,c : daun gambir. d,e : bunga gambir, f : pohon gambir

Tabel 2. Variabilitas fenotipik tanaman gambir di Desa Tanjung, Kec.Koto Kampar Hulu, Kab.Kampar

\begin{tabular}{lllll}
\hline No & Karakter & S $^{2}$ & St Dev & Kriteria \\
\hline 1 & Sudut cabang $\left(^{\circ}\right)$ & 2,15 & 1,29 & Sempit \\
2 & Panjang ruas $(\mathrm{cm})$ & 1,41 & 1,18 & Sempit \\
3 & Diameter cabang $(\mathrm{mm})$ & 1,52 & 1,21 & Sempit \\
4 & Permukaan cabang & 0,70 & 0,87 & Sempit \\
5 & Warna permukaan cabang & 2,61 & 2,14 & Sempit \\
6 & Bentuk helaian daun & 2,44 & 1,53 & Sempit \\
7 & Bentuk ujung daun & 0,26 & 0,44 & Sempit \\
8 & Bentuk pangkal daun & 1,25 & 1,13 & Sempit \\
9 & Panjang tangkai daun $(\mathrm{cm})$ & 0,04 & 0,22 & Sempit \\
10 & Diameter tangkai daun $(\mathrm{mm})$ & 0,11 & 0,34 & Sempit \\
11 & Panjang daun $(\mathrm{cm})$ & 1,48 & 1,21 & Sempit \\
12 & Lebar daun (cm) & 1,26 & 1,17 & Sempit \\
13 & Tebal daun (mm) & 0,06 & 0,22 & Sempit \\
14 & Luas satu helai daun $\left(\mathrm{cm}^{2}\right)$ & 321,2 & 22,47 & Sempit \\
15 & Bobot satu helai daun $(\mathrm{gr})$ & 0,31 & 0,64 & Sempit \\
16 & Permukaan atas daun & 0,42 & 0,67 & Sempit \\
17 & Permukaan bawah daun & 0,08 & 0,29 & Sempit \\
18 & Warna permukaan helaian daun & 3,46 & 1,91 & Sempit \\
& bagian atas & & &
\end{tabular}


19 Warna permukaan helaian daun bagian bawah

20 Warna tulang daun

21 Tepi daun
2,91

$\infty$

$\infty$

$\begin{array}{ll}1,31 & \text { Sempit } \\ \infty & \text { Sempit } \\ \infty & \text { Sempit }\end{array}$

terhadap 30 aksesi tanaman gambir di Desa Tanjung, Kec.Koto Kampar Hulu, Kab.Kampar, keseluruhan data diolah menggunakan program Numerical Taxonomy and Multivariate Analysis System versi 2.02.

Pola hubungan kemiripan tanaman gambir berdasarkan 21 karakter morfologi

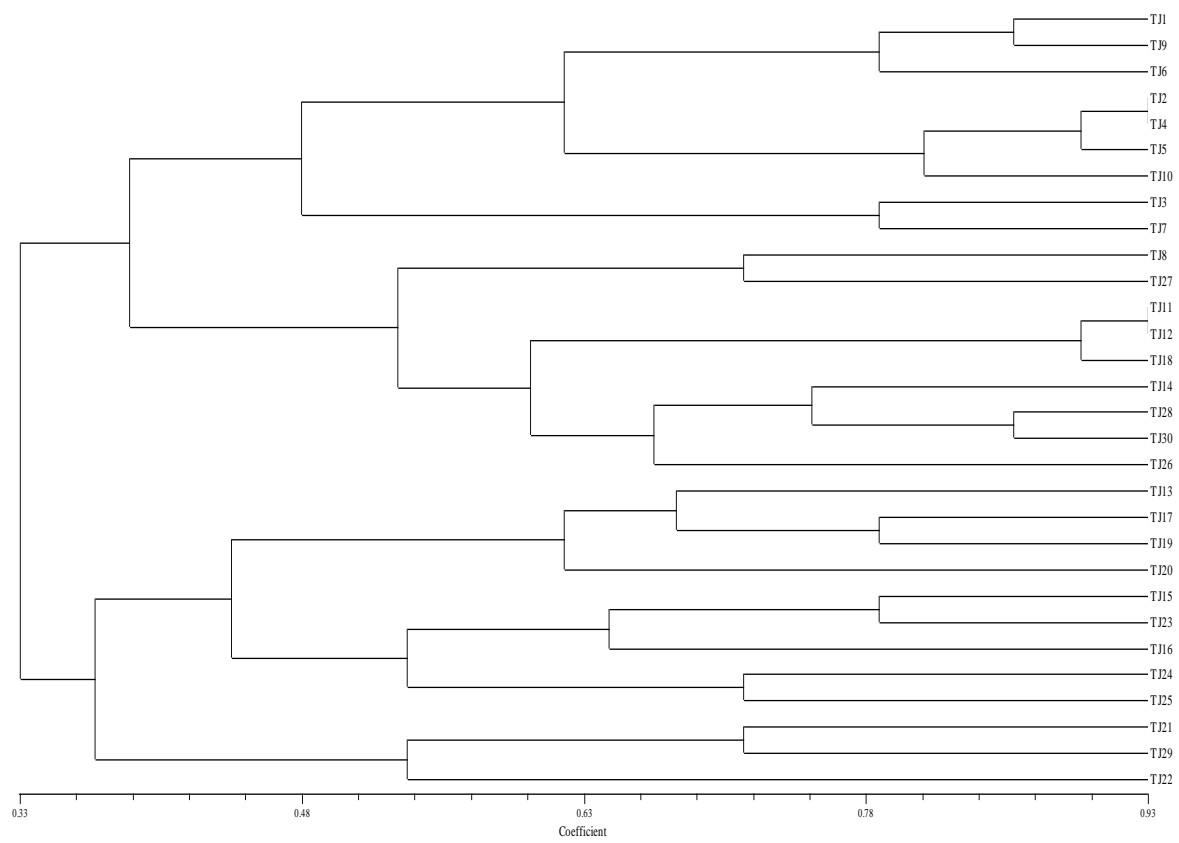

Gambar 2. Dendogram 30 aksesi tanaman gambir di lokasi pengamatan,

Analisis kemiripan tanaman gambir di Desa Tanjung, Kec.Koto Kampar Hulu, Kab.Kampar dari 30 aksesi dengan 21 karakter morfologi menghasilkan dendogram dengan koefisien kemiripan 0,33-0,93 atau 33-93\%, keseluruhan karakter morfologi bersatu pada koefisien 0,33 , terdapat 2 kelompok utama yaitu kelompok 1 dan 2 . Kelompok 1 terdiri atas 18 aksesi yaitu :

TJ1,TJ9,TJ6,TJ2,TJ4,TJ5,TJ10,TJ3,TJ7,T J8,TJ27,TJ11,TJ12,TJ18,TJ14,TJ28,TJ30 dan TJ26. Sedangkan Kelompok 2 terdiri atas 12 aksesi yaitu:
TJ13,TJ17,TJ19,TJ20,TJ15,TJ23,TJ16,TJ 24,TJ25,TJ21,TJ29,TJ22. Keseluruhan aksesi mengelompok pada koefisien 0,33. Aksesi tanaman gambir yang memiliki kemiripan fenotipik paling dekat yaitu aksesi TJ2 dengan TJ4, TJ11 dengan TJ12 dengan nilai kemiripan 0,93 . Syukur et al (2012) menyatakan bahwa semakin besar nilai angka koefisien kemiripan maka semakin besar pula tingkat kemiripan diantara tanaman yang dibandingkan. Sebaliknya semakin kecil angka koefisien kemiripan maka semakin kecil pula tingkat kemiripan tanaman tersebut. Artinya, semakin besar angka 
kemiripan maka semakin dekat tingkat kekerabatannya dan sebaliknya jika semakin kecil angka kemiripan maka semakin jauh kekerabatannya. Implikasi nya dalam pemuliaan tanaman, dengan

\section{KESIMPULAN}

Analisis kemiripan tanaman Gambir di Desa Tanjung,Kec.Koto Kampar Hulu,Kab.Kampar dari 30 aksesi dengan 21 karakter morfologi

\section{DAFTAR PUSTAKA}

Denian, A., dan Suherdi. 1992. Teknologi budidaya dan pascapanen gambir. Temu Tugas Aptek Pertanian Sub Sektor Perkebunan. 5 - 8 Oktober 1992. Bukittinggi

Denian, A., Z. Hasan, dan A. Taher. 2000. Status dan perkembangan penelitian tanaman gambir. Makalah disampaikan pada Seminar Sehari Teknik Budidaya dan Pengolahan Hasil Gambir dan Nilam di Padang tanggal 20 Januari 2000. 15 hal.

Denian. A. dan A. Fiani. 1994. Karakteristik morfologis beberapa nomor tanaman gambir. Prosiding Seminar Penelitian Tanaman Rempah dan Obat. Sub-Balitro Solok (4) : 29-30.

Denian. A., H. Idris, dan E. Suryani. 1992. Studi sifat-sifat morfologis beberapa tipe gambir di Sumatera Barat. Bul. Litro VII(2) : 21-25. adanya kekerabatan yang jauh maka akan diperoleh nilai heterosis tinggi,rekombinasi tinggi yang sangat penting untuk perakitan benih hibrida.

menghasilkan dendogram dengan koefisien kemiripan 0,33-0,93 atau 3393\%. Variabilitas fenotipik yang ditemukan di lapangan adalah sempit.
Fauza, H. 2005. Gambir (Uncaria gambir (Hunter) Roxb.). Dalam : Baihaki, A., Hasanuddin, Elfis, P. Hidayat, A. Sugianto, dan Z. Syarif (Eds.) Kondisi Berapa Plasma Nutfah Komoditi Pertanian Penting Dewasa ini. PPS Unpad - KNPN Litbang Deptan. hal 167-186.

Fauza, H. 2009. Identifikasi karakteristik gambir (Uncaria spp.)di Sumatera Barat dan analisis RAPD. Dissertasi. PPs Universitas Padjadjaran. Bandung. 308 hal.

Nazir, N. 2000. Gambir, Budidaya, Pengolahan, dan Prospek Diversifikasinya. Hutanku. Padang. 136 hal. 